\title{
Efetivação do uso de Tecnologias na Educação: Desafios na formação de recursos humanos
}

\author{
Márcia de Freitas Vieira ${ }^{1}$ \\ ${ }^{1}$ Universidade Aberta de Portugal \\ Palácio Ceia - Rua da Escola Politécnica, 147 - Lisboa - Portugal \\ marcia.ipatinga@gmail.com
}

\begin{abstract}
This work aims to contribute directly to the discussions regarding the formation of human resources for the use of information and communication technologies in education. Essentially bibliographical, considered as main sources of scientific research reports of experiences on the implementation of ICT in education. Based on the study reports, confirms the need to develop teaching skills to use ICT in a critical view and proposes some alternatives to teacher training for the technologies to be effectively incorporated into the pedagogical practices of teachers.
\end{abstract}

Resumo. Este trabalho objetiva contribuir diretamente com as discussões referentes à formação de recursos humanos para a utilização das Tecnologias da Informação e Comunicação na educação. De cunho essencialmente bibliográfico, considera como principais fontes de pesquisa relatos científicos de experiências sobre a aplicação da TIC na educação escolar. Com base nos relatos estudados, ratifica a necessidade de desenvolvimento de competências docentes para uso das TIC numa visão crítica e contextualizada e propõe algumas alternativas para a formação docente para que as tecnologias sejam efetivamente incorporadas nas práticas pedagógicas dos professores.

\section{Introdução}

Refletindo sobre as perspectivas futuras de efetivação do uso das tecnologias de Informação e Comunicação (TIC) em prol da aprendizagem, dois grandes desafios merecem atenção: o desafio na produção de softwares efetivamente educacionais e a formação de professores em Informática na Educação.

Quanto ao primeiro, novas concepções que geram novas soluções tecnológicas, novos designs e novos modelos de negócios de base tecnológica para demandas da Educação germinam nas grandes universidades e em muitas softwares houses do país. Contudo, grande parte dos softwares multimídia carece de conteúdo educacional ou científico incorporado. As empresas informáticas ainda não têm o conhecimento interdisciplinar, para produzirem softwares de efetivo alcance educacional, embora tecnicamente tenham todas as ferramentas de softwares possíveis.

Por outro lado, a rápida evolução tecnológica da atualidade demanda uma formação inicial e uma educação continuada concernente com o papel dos educadores e às necessidades pedagógicas da sociedade da informação que traz novas possibilidades, 
novas metodologias e demanda dos responsáveis pelo sistema acadêmico repensarem conceitos tradicionais do atual sistema educacional.

Em tempos de internet e suas múltiplas aplicações, a estrutura tradicional de ensino não atende aos paradigmas atuais, voltados para o mundo virtual. A escola não é mais o espaço privilegiado do saber, nem o professor a principal fonte de transmissão do conhecimento. Neste cenário, o professor emerge como o principal responsável pela utilização efetiva das TIC no ambiente escolar e pelas transformações na prática pedagógica que essas tecnologias propiciam, tendo papel essencial na mediação pedagógica entre a interação do educando com os recursos tecnológicos. Ele não será substituído, porém tem agora um grande arsenal de novas metodologias para cumprir a sua missão. Como diferenciá-las e aplicá-las?

Muitas escolas estão equipadas com a realidade virtual, que permitem aos alunos explorar um local, um objeto ou um tema de uma maneira completamente imersa e interativa. Aulas em videoconferências e a interatividade abrem novas oportunidades e atrativos para o aprendizado, além de poder atingir um número bem maior de alunos. Os livros passam a ser eletrônicos e interativos e os jogos e simuladores são complementados por programas educacionais. Qual seria a sequência pedagógica e didática ideal para utilização desses recursos no processo ensino-aprendizagem?

Até agora, a tecnologia digital não foi usada com toda a sua potencialidade nas escolas. A aparente causa do desuso das tecnologias na escola e, mais recentemente da internet, pode esconder conflitos de gerações entre imigrantes ${ }^{1} \mathrm{e}$ nativos ${ }^{2}$ digitais (Prensky, 2001).

Para Bernini (2010), o uso das TIC na sala de aula não é novidade, mas cabe ao professor selecionar os programas computacionais, dando a eles uma intencionalidade clara e que justifique sua utilização, para que os recursos tecnológicos possam ser um meio facilitador da aprendizagem e não algo introduzido sem objetivo.

Diversos autores, entre eles, Marinho (2013), Molin e Raabe (2012), Vieira (2013), mostram que o número de professores que usam o computador no processo ensino-aprendizagem é ainda pequeno e este uso se restringe aos laboratórios de informática das escolas. Como tais ambientes de aprendizagem, com suas características hipermediais e interativas, que os alunos, em sua maioria, já dominam, podem ser trabalhadas por professores que, geralmente, pouco as conhecem?

Acreditando que a resposta para essas questões encontra-se na formação docente, este trabalho objetiva contribuir diretamente com as discussões referentes à formação de recursos humanos para a utilização das Tecnologias da Informação e Comunicação na educação e propor algumas ações para a formação docente para que as tecnologias sejam efetivamente incorporadas nas práticas pedagógicas dos professores.

Dessa forma, as próximas seções descreve a motivação e a metodologia utilizada para realização do trabalho, apresenta o referencial teórico que sustenta a discussão, discute os resultados obtidos e tece algumas considerações finais.

\footnotetext{
${ }^{1}$ Nativos Digitais são todos aqueles que nasceram com a tecnologia e são fluentes na linguagem digital dos computadores (Prensky, 2001).

${ }^{2}$ Imigrantes Digitais são todos aqueles que falam a linguagem digital, mas que revelam dificuldades em compreender e expressar-se digitalmente (Prensky, 2001).
} 


\title{
2. Motivação do estudo e metodologia
}

Ao acompanhar a implementação de laboratórios de informática nas escolas públicas municipais de Ipatinga/MG, desde a sua concepção, em julho de 2005, a dezembro de 2006, através de um estudo de caso, Borges (2007) concluiu:

\begin{abstract}
Os resultados desta investigação apontam para a importância da atuação do professor para a mediação pedagógica em ambientes informatizados de aprendizagem e mostram a necessidade de um programa de formação permanente dos docentes que estimule e dê possibilidades ao professor de integrar as atividades dos softwares educacionais ao conteúdo curricular de suas disciplinas (p.146).
\end{abstract}

Ao retornar ao ambiente de pesquisa, em 2013, no intuito de verificar a situação atual de utilização dos laboratórios de informática e como tem sido a utilização dos mesmos, após oito anos de implantação do Projeto, Vieira (2013) constatou que "os poucos professores que ainda utilizam os laboratórios, o fazem como desejam, sem o acompanhamento pedagógico e muitas das vezes, é mais um momento de descontração para os alunos" (p.305) e que o despreparo dos professores para utilizar a tecnologia no processo educacional é a principal causa para a subutilização dos recursos computacionais na educação no país. A realidade constatada por Vieira (2013) foi o fator motivador para este estudo.

De cunho essencialmente bibliográfico, este trabalho considera como principais fontes de pesquisa, relatos científicos de experiências sobre a aplicação da TIC na educação escolar e de formação docente bem sucedida. Fundamentou-se na busca de respostas às seguintes questões: Que competências devem ser adquiridas pelo docente para utilizar as TIC de forma a transformar as práticas tradicionais de sala de aula? Os programas de formação voltados para o uso das TIC têm sido adequados e suficientes para qualificar os docentes e integrar, efetivamente, esta tecnologia à prática pedagógica? Que ações tem surtido efeito positivo nos modelos de formação já utilizados?

\section{O domínio tecnológico do aluno desafia a pedagogia}

Um número cada vez maior de crianças e jovens tem chegado às escolas como usuários frequentes de todo tipo de tecnologia, como por exemplo: telefones celulares, tablets, computadores, videogames, entre outros. E via de regra, se sentem desmotivados e entediados ao terem que passar horas em uma sala de aula tradicional - como quadro negro, livros impressos, cadeiras enfileiradas e aula expositiva.

Problemas com indisciplina, baixo aproveitamento e má vontade dos jovens em relação à escola mostram que o modelo educacional atual está defasado. O mundo hipermediático, dos sons e dos movimentos, não fazem parte do universo escolar. Envolvidos numa rotina rica em tecnologia, estudantes inovam na maneira como aprendem e buscam conhecimento, se movimentam facilmente pelo ciberespaço ${ }^{3}$, transpõem barreiras geográficas na interação com outros, produzem e consomem conhecimento de maneira totalmente adversa da tradicional, enquanto a escola ainda está baseada em um modelo unidirecional de "1 para muitos", na oralidade e no texto. Livros e enciclopédias eram as principais ferramentas de pesquisa até o início da década

\footnotetext{
3 Indica o universo de informações e interações humanas possibilitadas pelos meios materiais de comunicação digital (Lévy, 1999).
} 
de 90, quando os computadores começaram a chegar aos lares no Brasil. Hoje, o aluno pode acessar inúmeras enciclopédias virtuais das maiores universidades do mundo, a partir de um clique no mouse do computador.

Essa transformação nos modos de buscar informações, conhecimento e comunicação diferem do modo de trabalhar e interagir da maioria dos professores, imigrantes no ciberespaço (Prensky, 2001). Os docentes, formados na cultura da oralidade, ainda fazem uso, quase que exclusivo, dos meios tradicionais de ensino. Portanto, essas diferentes formas de pensar e interagir no mundo seriam a causa de muitas das dificuldades que ocorrem atualmente quando nativos e imigrantes digitais se encontram no mesmo espaço: a sala de aula.

No entanto, a escola e o professor parecem desconhecer a realidade cibernética da nossa sociedade. Além das deficiências na formação docente, outro componente do problema de integração das TIC na escola é a gestão de tecnologias em redes públicas de educação, em nivel municipal e estadual. Ainda é comum laboratórios de informática subutilizados ou fechados por meses e anos em escolas públicas. Não há utilização de sistemas informatizados de gestão de tecnologias nas escolas, que possam ajudar gestores a detectar problemas e incentivar o uso de TIC disponíveis.

As instituições de ensino falham ao ignorar esses espaços virtuais. Professores e instituições precisam utilizar esses espaços que, hoje, ainda são limitados em muitas escolas. De acordo com Silva (2008), "se a escola não inclui a internet na educação das novas gerações, ela está na contramão da história, alheia ao espírito do tempo e, criminosamente, produzindo exclusão social ou exclusão da cibercultura".

Neste atual contexto educacional, é urgente a necessidade de mudança da atividade docente: de "transmissor de conhecimento" para um "facilitador da aprendizagem". Tira-se o foco do ensino e "joga-se a luz" sobre a aprendizagem, e assim as TIC propiciam um ambiente para que o estudante tenha várias possibilidades de aprendizagem, além do espaço escolar físico tradicional. $\mathrm{O}$ desafio docente é transformar as informações que estão na internet (nas diferentes mídias) em conhecimento, e para isso podem ressignificar as metodologias tradicionais, e também utilizar as TIC para complementar ou permitir novos ambientes de aprendizagem (Coll,2004).

As TIC têm se mostrado capazes de transformar os diversos contextos educativos tradicionais e potencializar para a educação os não convencionais, além de criar novos ambientes de aprendizagem, como os do espaço cibernético (redes sociais, plataformas formativas, fóruns, entre outros). Coll (2004) defende que a TIC é uma potencialidade no processo ensino-aprendizagem baseada na teoria sócio-interacionista de Vygostsky, com uma relação entre os conteúdos, alunos e professores, conforme o triângulo didático apresentado por ele: conteúdo (objeto de ensino-aprendizagem), a ação do professor (ensino) e a ação do estudante (aprendizagem). Desta forma, o acesso seria mais facilitado, mas teria a necessidade de uma aplicação didática para a aprendizagem. Pode-se perceber que a interatividade, dinamismo, multimídia, hipermídia e conectividade propiciam ao aprendiz um aumento de sua autonomia e percepção do protagonismo no processo ensino-aprendizagem.

As novas mídias sociais (blogs, wikis, youtube, facebook, twitter, linkedin, delicious, Flickr, SlideShare, entre outras), agregam um grande potencial para a aprendizagem autônoma e para a criação de novas culturas de aprendizagem e de 
trabalho coletivo. Neste contexto, é importante questionar que saberes e que competências deverão adquirir crianças e adolescentes para que possam tirar partido do potencial das mídias sociais e das culturas que eles configuram e explorar com sucesso as oportunidades que o mundo lhes oferece (Figueiredo, 2010).

O professor deve estar consciente de seu papel e da mudança de sua função nesse processo educativo. Portanto, o impacto das TIC exercido sobre as práticas educativas está mais dependente da sua utilização pedagógica e nem tanto da natureza nem das características das tecnologias empregadas (Coll, 2004).

\section{Tecnologias digitais no sistema educacional: e a formação docente?}

Entretanto, estudos recentes ${ }^{4}$, realizados no âmbito de programas de pós-graduação no Brasil, sugerem que os níveis de resistência à introdução de inovação baseada nas TIC nas escolas ainda é alto e apresentam as dificuldades que as escolas enfrentam para o uso efetivo da tecnologia no processo educacional. Dentre elas, a mais citada, é o despreparo dos professores para o uso pedagógico das TIC no contexto educacional.

A partir de um estudo do Projeto de Inclusão Digital de Ipatinga/MG, Borges (2007) apresenta as estratégias empregadas pela Secretaria de Educação do município para inserir o processo educacional do município, e sua gestão, no novo paradigma da sociedade moderna, através da instalação de laboratórios de informática, nas escolas municipais de Ipatinga. Os resultados desta investigação apontam para a deficiência na formação dos professores para articulação dos conteúdos curriculares trabalhados em sala de aula com os softwares do laboratório de informática. Assim, um recurso que poderia contribuir na prática diária dos professores encontra-se ainda subutilizado.

Outro estudo semelhante foi realizado por Gomes (2011), que investigou como as escolas públicas e particulares do município de Florianópolis/SC estão se apropriando dos recursos informatizados. Concluiu que, mesmo em escolas dotadas com tecnologia atual e sofisticada, o maior impedimento para uma prática pedagógica inovadora diz respeito às dificuldades que os professores encontram em recorrer a estes recursos.

Também Alvarenga (2011), em sua pesquisa de doutorado, aponta que $85 \%$ de uma amostra de 253 professores do ensino médio de escolas públicas estaduais de Campinas/SP sentem-se inseguros para utilizar tecnologias no ensino, em situações que envolvem este uso com os alunos. A pesquisa, feita em 27 escolas do município entre 2009 e 2010, mostrou ainda que os professores com menos tempo de formação e de experiência docente têm mais motivação para ensinar utilizando as novas tecnologias.

Percebe-se assim, que a implantação de laboratórios de informática em todas as escolas públicas do país, prometida pelo governo federal, tem esbarrado no despreparo dos professores para usar o computador no processo educacional. Observa-se na maioria das escolas uma subutilização de equipamentos porque os professores não sabem usálos como ferramentas de ensino.

E essa não é uma realidade apenas do Brasil. A partir de um estudo de caso múltiplo, sobre a competência e a confiança dos professores do ensino básico no uso das

\footnotetext{
${ }^{4}$ Alvarenga (2011), Borges (2007), Gomes (2011), Marinho (2013), Molin e Raabe (2012), Tono(2008), Vieira (2013), entre outros.
} 
TIC nas práticas educativas, realizado em cinco países europeus (Espanha, Grécia, Holanda, Itália e Portugal), Peralta \& Costa (2007) apontam que as TIC ainda não são um recurso integrado nas atividades de ensino. Os professores sabem usar o computador, mas não em sala de aula com os seus alunos e os professores que usam as TIC não alteraram significativamente as atitudes, os papéis, e as formas de ensinar e de aprender. E concluem que "não há muitos professores competentes no uso das TIC no ensino, pelo que se torna necessário investir na sua re-educacão" (p.85). Afirmam ainda que essa responsabilidade deva ser assumida pelas instituições de ensino superior responsáveis pela sua formação.

O que denota-se dos relatos acima vai ao encontro ao que diz Costa (2004), no sentido de que o problema da integração curricular das TIC reside, em parte, nas dificuldades que os docentes apresentam em compreender as potencialidades das novas ferramentas e das formas como estas podem ou devem ser integradas no quotidiano das escolas. Contudo, "Ainda hoje as escolas têm toda a sorte de dificuldades para capacitar seus professores em Informática” (Marinho, 2013, p.268).

É evidente que a capacitação de professores para o uso da informática na educação, especificamente o computador como ferramenta pedagógica, é muito importante, visto que durante sua formação acadêmica os professores não tiveram, em sua graduação, disciplinas que refletissem sobre o uso dos recursos informáticos na sala de aula. Para Sales \& Fichmann (2013, p.271), "O grande desafio hoje para o professor é a apropriação, no contexto formativo, das ferramentas digitais, seguido do reconhecimento das possibilidades de uso pedagógico".

Odorico (2012) ressalta que "em geral, o professor não recebeu formação para o uso pedagógico da ferramenta computacional" e que os professores também "não se sentem confortáveis com o uso das novas tecnologias em sala de aula" (p.7). Destarte, criando oportunidades e dando-lhes condições para desenvolver competências para uso dos recursos tecnológicos no processo ensino-aprendizagem, os educadores vencem as resistências e procuram empregá-las na prática docente de maneira eficaz e eficiente, visando a construção colaborativa e participativa do conhecimento.

\section{Construindo competências para o uso da tecnologia na sala de aula}

O investimento na construção de competências docentes é o diferencial entre escolas com rica infraestrutura tecnológica e escolas reconhecidamente de boa qualidade e fator preponderante nos casos de sucesso no uso das tecnologias digitais na escola.

Perrenoud (2000) aponta a utilização das TIC na dinâmica pedagógica como uma das competências necessárias aos professores que, sensíveis às mudanças sociais, desejam ensinar e promover a aprendizagem. Contudo, a simples utilização das TIC não constitui competências para favorecer aprendizagem. Somente adquirindo novas competências, o professor poderá adotar uma nova perspectiva da aprendizagem, em substituição ao ensino instrucionista.

$\mathrm{Na}$ perspectiva das novas matrizes curriculares, visando atender as atuais necessidades do ambiente educacional, os principais processos a serem reconstruídos dizem respeito às funções e aos papéis docentes. As competências docentes envolvem a competência técnica, não mais restrita ao domínio de conteúdos específicos de disciplinas específicas, mas a sua articulação às múltiplas conexões descentralizadas, e 
ao compromisso político da docência, que não pode mais estar fundado na transmissão pura e simples dos conteúdos, mas articulado às novas determinações sociais, como o acesso a conteúdos relevantes, informações significativas, estratégias pedagógicas flexíveis e hipermidiáticas.

Adquirir essa competência é uma oportunidade valiosa para o professor deste terceiro milênio, pois, enquanto ensina e atua junto a seus alunos, também aprende, reflete sobre sua prática, sobre os fatos sociais e conhecimentos culturalmente produzidos, cresce profissionalmente e valoriza sua profissão. Segundo Peralta \& Costa (2007) a competência e a confiança dos professores são, realmente, "fatores decisivos na implementação da inovação nas práticas educativas" (p.78).

Sobre a competência do professor quanto ao uso adequado das tecnologias Kenski (2012, p. 77) afirma:

É necessário, sobretudo, que os professores se sintam confortáveis para utilizar esses novos auxiliares didáticos. Estar confortável significa conhecê-los, dominar os principais procedimentos técnicos para sua utilização, avaliá-los criticamente e criar novas possibilidades pedagógicas, partindo da integração desses meios com o processo de ensino.

Nesta linha de pensamento, Freitas (2010) defende a oferta de disciplinas que tratam dos usos do computador/internet na prática pedagógica, nas matrizes curriculares e nos projetos pedagógicos dos cursos de Licenciatura e Pedagogia, e discute as deficiências na formação oferecida por grande parte dos cursos, que não formam seus alunos para a sociedade do conhecimento. Relata ainda, que algumas Instituições de Ensino Superior, preocupadas com este cenário, ofertam cursos à distância, influenciando positivamente as práticas docentes.

Diante do cenário contemporâneo, em que os papéis do professor e do estudante são ressignificados, os espaços e tempos possibilitam outras formas de experimentação. Nesse contexto, Mill (2010) propõe a EaD como modalidade de formação docente, ressaltando a EaD como um dos grandes catalisadores das transformações que a educação brasileira necessita, desde que prime pela qualidade da formação e pela melhoria da formação do futuro cidadão.

De acordo com Barcelos (2011, p.09), "a formação é contínua, ao longo da vida assim como também, novas tecnologias são criadas continuamente." Isso exige redefinição das metodologias de ensino, reflexão sobre as práticas de sala de aula, e adequação às transformações científicas e tecnológicas. Só assim, as TIC serão efetivamente incorporadas na prática docente. Dessa forma, o sucesso do uso das TIC na educação está ligado intrinsecamente a formação dos professores.

Essa afirmação é comprovada no estudo de Rabelo (2008) que mostra resultados positivos de mudanças ocorridas na prática docente de professores da rede estadual de ensino, que participaram de cursos de capacitação em Informática Educativa no Núcleo de Tecnologia Educacional, de Vitória da Conquista/Ba.

Percebemos que os professores ficam "encantados" com todas as possibilidades apresentadas pelos recursos tecnológicos, não somente os ligados ao computador e a rede Internet, mas também com as propostas trabalhadas para o uso de recursos já bem mais conhecidos como TV e vídeo, e se sentem mais estimulados e preparados para realizar atividades pedagógicas com o uso desses recursos (Rabelo,2008,p.412). 
Outra iniciativa de sucesso é a relatada por Sales \& Fichmann (2013) que apresentam os resultados da implementação de dois cursos de formação de professores da Educação Básica de Fortaleza com o objetivo de "mostrar caminhos possíveis para a integração de tecnologias digitais aos conteúdos curriculares em ambientes virtuais de forma motivadora, dinâmica e colaborativa" (p.270). Para os autores, "as redes de aprendência" propiciam o desenvolvimento das competências docentes para o século XXI e a renovação de suas práticas.

A experiência de formação continuada demonstrou que é possível desenvolver competências no uso de tecnologias digitais a partir do uso de redes de aprendência, com fundamentação e metodologia transdisciplinar. Foi possível a integração de diversos recursos e ambientes online às práticas pedagógicas dos professores, com possibilidade de trabalho em múltiplos espaços: no laboratório de informática, na sala de aula e em ambientes virtuais (Sales \& Fichmann, 2013, p. 278).

A pesquisa de Sales (2012) também revela que uma boa formação resulta na "percepção de novas formas de ensinar e aprender" [...] e "o favorecimento de mudança em sua ação e postura docente"( p.9), o que indica que os resultados da formação de professores vão além de um contato com máquinas e programas, mas no estímulo a inovações no processo ensino aprendizagem.

\section{Considerações finais}

A incorporação das tecnologias na sala de aula somente irá ocorrer quando os professores trabalharem com as tecnologias, pois a integração com o conteúdo curricular vem com a prática. E a própria tecnologia permite o contato com mais informação e conhecimento sobre essa integração. Nesse sentido, o professor precisa estar em contato com as tecnologias e as universidades precisam mediar a inclusão de reflexão e aporte teórico para dar suporte a esta formação.

Com base nas experiências no campo da utilização das TIC no contexto educativo, relatadas aqui, podemos afirmar que a tecnologia por si só, por mais recursos e potencialidades para a aprendizagem que possam ter, não melhora a aprendizagem e a qualidade do ensino. A tecnologia e os objetos de aprendizagem só têm sentido em um momento de aprendizagem. É preciso criar situações de aprendizagem e de interação, para construir o processo do conhecimento. Não é só disponibilizar tecnologia, é necessário a atuação/interação do professor, de sua vivência e competência profissional. A ação humana é que potencializa o uso da tecnologia e dá sentido à ferramenta. $\mathrm{O}$ uso que fazemos dela é que faz a inovação. A tecnologia é uma forma de mediação, as pessoas é que fazem o processo educativo. É preciso reconhecer que melhores recursos, não implicam melhores aprendizagens; que inovações tecnológicas não implicam inovações pedagógicas; que todo processo educativo se fundamenta em paradigmas comunicacionais e educacionais.

Dar uma finalidade e um uso pedagógico às TIC no contexto do triângulo didático citado por Coll(2004), induz uma maior motivação nos estudantes e no professor, com um impacto positivo nos resultados de aprendizagem, porque se modificam as práticas educativas e os processos de ensino-aprendizagem. É fundamental que o Governo estabeleça políticas públicas de formação continuada de professores, incorporando ferramentas em seu fazer docente, de forma a prepará-los para se adaptarem às novas tecnologias e serem capazes de utilizá-las no processo ensino-aprendizagem (Reis \& Silveira, 2012). 
Evidencia-se a extrema necessidade de se fazer um esforço educacional e de pesquisa no Brasil visando o desenvolvimento de competências docentes para uso das TIC numa visão crítica e contextualizada. Dessa forma, professores estarão mais preparados para melhor apoiar essa geração de nativos digitais e os alunos, por sua vez, mais integrados ao ambiente escolar, mais colaborativos, comunicativos, e mais preparados para um futuro profissional de sucesso.

Importante lembrar aqui, a inserção do Profissional Licenciado em Ciência da Computação e sua real posição nesta conjuntura. São profissionais com conhecimento das últimas tendências da área, com ampla formação teórica, tecnológica, pedagógica e humana, e portanto, capazes de gerar inovações nos processos de ensino e aprendizagem. Além do exercício profissional de magistério em computação na Educação Básica, e da capacitação na elaboração e aplicação de projetos de informática educativa, estes profissionais podem atender à demanda crescente das escolas, contribuindo na formação de professores para um mundo em constantes transformações científicas, tecnológicas e culturais, sendo agentes capazes de promover um espaço para a interdisciplinaridade, a comunicação e a articulação, entre as diversas disciplinas e áreas do conhecimento do currículo escolar, com rigor científico tecnológico e didático pedagógico.

As universidades brasileiras, nos cursos voltados para educação em computação, têm o desafio de proporcionar esse conhecimento interdisciplinar e diversificado. É nelas que se concentra o conhecimento pedagógico, social e humano, aliado aos conhecimentos especializados das ciências exatas. O alicerce educacional cria e mantém a estrutura necessária para produzir e fazer chegar às escolas softwares educacionais de qualidade e para formar docentes conscientes de seu papel social e da sua contribuição no avanço científico e tecnológico do país.

\section{Referências bibliográficas}

Alvarenga, C. E. A. (2011). Autoeficácia de professores para utilizarem tecnologias de informática no ensino. Campinas, Unicamp (Tese de doutorado).

Barcelos, Gilmara Teixeira (2011). Tecnologias na prática docente de professores de matemática: formação continuada com apoio de uma rede social na internet. 332p. Centro de Estudos Interdisciplinares em Novas Tecnologias da Educação, UFRGS, Porto Alegre (RS). Disponível em: <http://hdl.handle.net/10183/48918>. Acesso em 09/04/2015.

Bernini, D. S. D. (2010) Formação de professores com e para o uso das Tecnologias da Informação e Comunicação. Anais do $16^{\circ}$ Worshop de Informática na Escola, Belo Horizonte - MG. Disponível em http://www.br-ie.org/pub/index.php/wie/article/view/2026. Acesso em abril/2015

Borges, M. F. V. (2007). Inserção da informática no ambiente escolar: Inclusão digital e laboratórios de informática numa rede municipal de ensino. Belo Horizonte, Cefet-MG (Dissertação de mestrado).

Coll, C. (2004). Psicología de la educacíon y práticas educativas mediadas por las tecnologias de la información y la comunicación. Disponível em http://virtualeduca.org/ifd/pdf/cesarcoll-separata.pdf. Acesso em novembro/2013

Costa, F. (2004). O que justifica o fraco uso dos computadores na escola. Polifonia, Lisboa: Edições Colibri, n. ${ }^{\circ}$, p.19-32. Disponível em http://repositorio.ul.pt/handle/10451/6088. Acesso em fevereiro/2014 
Figueiredo, A. D. (2010). A Geração 2.0 e os novos saberes. Seminário 'Papel dos Media' das Jornadas "Cá Fora Também se Aprende", Conselho Nacional de Educação (no prelo). Acessado em fevereiro/2014 em https://coimbra.academia.edu/adf.

Freitas, M. T. A (2010). Convergências entre a EAD e o ensino presencial na formação de professores. In: Convergências e tensões no campo da formação e do trabalho docente. Belo Horizonte: Autêntica, p. 354-372.

Gomes, N. G. (2011). Os computadores chegam à escola: E agora professor. Disponível em http://www.comunic.ufsc.br/artigos/art_computador.pdf. Acesso em fevereiro/2014

Lévy, P. (1999). Cibercultura. Rio de Janeiro: Editora 34.

Marinho, Vanessa C (2013). O cenário do uso das tecnologias na escola do século XXI. Anais II Congresso Brasileiro de Informática na Educação. Disponível em http://www.brie.org/pub/index.php/wie/article/view/2605. Acesso em abril/2015.

Mill, D. (2010). Reflexões sobre a formação de professores pela/para educação a distância na contemporaneidade: convergências e tensões. In: Convergências e tensões no campo da formação e do trabalho docente. Belo Horizonte: Autêntica, p. 354-372.

Molin, S. I. L.; Raabe, A. (2012) Novas Tecnologias n Educação: Transformações da Prática Pedagógica no Discurso Do Professor. Anais do $18^{\circ}$ WIE 2012. Disponível em http://www.br-ie.org/pub/index.php/wie/article/view/2104. Acesso em julho/2013.

Odorico, Elizandra K. (2012). Análise do Não Uso do Laboratório de Informática nas Escolas Públicas e Estudo de Caso. Anais do WIE 2012. Disponível em http://www.brie.org/pub/index.php/wie/article/view/2087/1854. Acesso em outubro/2013.

Peralta, H. \& Costa, F. (2007). Competência e confiança dos professores no uso das TIC. Síntese de um estudo internacional (versão on-line). Sísifo. Revista de Ciências da Educação, 3, p.77-86. Disponível em http://sisifo.fpce.ul.pt. Acesso em fevereiro/2014.

Perrenoud, P. (2000). 10 Novas competências para ensinar. Porto Alegre: Artes Médicas.

Prensky, M. (2001). Digital natives, digital immigrants. Acessado em outubro/2013 em http://www.marcprensky.com/writing/.

Rabelo, E. M. S. (2008). Capacitação de professores em informática educativa e seus reflexos na prática pedagógica. XXVIII Congresso SBC. Belém do Pará, PA: Anais SBC 2008.

Reis, Luiz Carlos; Silveira, Ismar Frango (2012). Políticas públicas para Formação de Professores em Informática na Educação: Desafios Nacionais e o Cenário Atual no Estado de São Paulo. Anais Workshop de Desafios da Computação Aplicada à Educação 2012. Acesso em abril/2015 em http://www.br-ie.org/pub/ index.php/desafie/article/view/2790.

Sales, Selma B.; Cruz, Alba Liarth (2012). Uma Experiência de Formação de Professores para o Uso das Ferramentas Digitais e Criação de Redes de Aprendência. Anais do WIE 2012. Acesso em maio/2015 em: http://www.br-ie.org/pub/index.php/wie/article/view/2128/1894.

Sales, Selma B.; Fichmann, Silvia (2013). Redes de Aprendência: uso de tecnologias digitais e formação de professores. Anais II Congresso Brasileiro de Informática na Educação. Acesso em abril/2015 em http://www.br-ie.org/pub/index.php/wie/article/view/2606/0.

Silva, M. (2008). Internet na educação e inclusão social na era digital, na sociedade da informação e na cibercultura. Rio de Janeiro: EDUERJ.

Tono, C. C. P., Cantini, M. C., \& Freitas, M. C. D. (2008). Políticas públicas de inclusão digital no Paraná - 1997 a 2006. Anais do XIX SBIE, Belém, PA.

Vieira, Márcia de Freitas (2013). 8 Anos de Informática na Educação nas Escolas Públicas Municipais de Ipatinga/MG: avanços e retrocessos. Anais do XIX WIE, Campinas, SP. 